\title{
POST PROCESSING AND ANALYSIS OF STORM SURGE: A CASE STUDY OF HUDHUD AND PHAILIN CYCLONES
}

\author{
Preethi. K., ${ }^{*}$, Murty.P.L.N ${ }^{2}$ \\ ${ }^{1}$ National Institute of Technology Karnataka, Surathkal, Karnataka - preethikonkathi@gmail.com \\ ${ }^{2}$ Earth System Science Organisation (ESSO)-Indian National Centre for Ocean Information Services (INCOIS), Hyderabad, India
}

Commission V, SS: Disaster Monitoring, Damage Assessment and Risk Reduction

KEY WORDS: Storm surge, Mesh generation, Post processing, Inundation

\begin{abstract}
:
Tropical cyclones affect the east coast of India due to its distinctive topography which is formed with a network of estuaries, bays, rivers, and inlets that causes inland flooding. The inland inundation of sea water is inflicting severe damage to the life and property. The ocean water entering the beachfront zone results to storm surges. In order to mitigate these storm surges, real-time monitoring and warnings are essential. For better visualization and analyzing the outputs from storm surge models, efficient post-processing tools are required. Hence post-processing of storm surge using GIS is carried out for taking protective measures. Storm surge vulnerable locations along the east coast of India have been identified in perspective of the number of storm surge events. Blue Kenue and SMS softwares are used to generate the unstructured triangular mesh over the study domain. Cyclones Phailin and Hudhud are selected in the current study and the associated surge heights and inundation extents are examined.
\end{abstract}

\section{INTRODUCTION}

The tropical cyclones formed over the Bay of Bengal are often propagating towards the east coast of India. These tropical cyclones generated storm surges results in severe damage to life and properties of the coastal population. The rapid increase of population along the coastal regions and vulnerability of coastal regions due to storm surge featured the significance of real-time monitoring, prediction, and early warning centers. The loss of life and property gets multiplied as the sea water inundates coastal areas. The surveillance and warning of storm surges are the utmost important parameters to be considered. Recently very severe cyclonic storms Phailin in the year 2013 and Hudhud in 2014 affected the east coast of India and resulting severe loss of life and destruction of coastal infrastructure (Lakshmi et al.2017.) are chosen for post processing of storm surge during these cyclones. Geographic information systems (GIS) can assume a critical part in post-preparing spatial data and help yield handling of storm surge. This helps in better understanding of vulnerability in coastal areas (Ferreira et al.2014.).The main objectives of the present study are (i) To generate unstructured mesh using Blue Kenue (open source) and SMS (commercial) software, (ii) to post process the storm surge model outputs using Arc Map.

\section{STUDY AREA}

The present study area is mainly focused along the east coast of India located middle of Latitude: $15^{\circ} 16.9173^{\prime} \mathrm{N}$ and Longitude: $83^{\circ} 17.3579^{\prime} \mathrm{E}$ as it is more vulnerable to storm surges due to its low to medium type of topography.

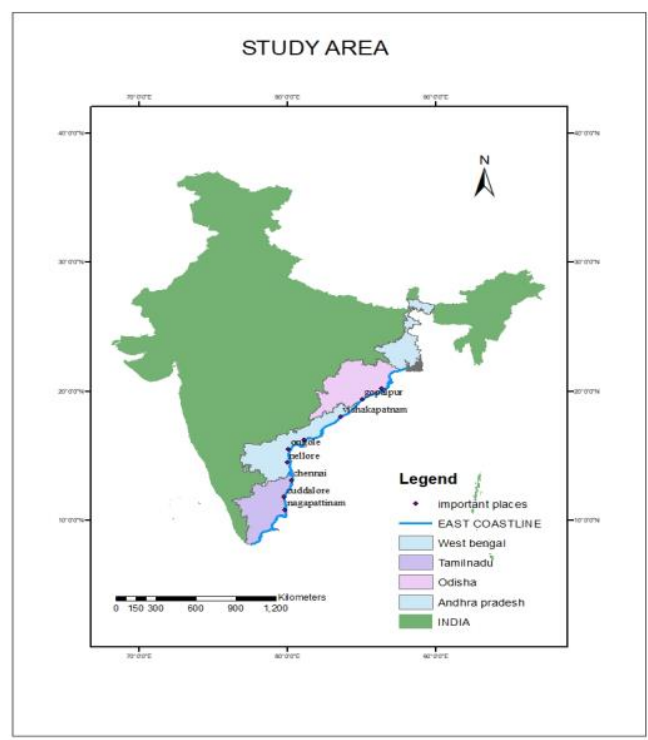

Figure1. Study Area

\footnotetext{
* Corresponding author
} 
The east coast of India has an extent of $2500 \mathrm{~km}$ of coastline which extended over four major states namely Tamilnadu, Andhra Pradesh, Orissa, and West Bengal. The Ganges, Krishna Mahanadi, and the Godavari are major rivers flowing into the Bay of Bengal. At the estuaries of these rivers, enormous siltation and evolution of sand bars fits best for the procreation of storm surge.

\subsection{Data used}

Bathymetry Data: The General Bathymetric Chart of the Oceans (GEBCO) provides bathymetry datasets for oceans which are available publically. Bathymetry data is downloaded from GEBCO and, the bathymetry points are extracted using ARC Map.

Mainland Data: Zero meter contour (coastline) and $10 \mathrm{~m}$ height contour are extracted using ARC Map storm surge Model Outputs:

FORT.14: ADCIRC Grid and Boundary Information File. It is an input file for the ADCIRC model which contains information about bathymetry/topography and node and elements in the grid

MAXELE.63: Maximum Elevation All Nodes in the Model Grid file. It is an output file of ADCIRC model which contains information about maximum elevation at each node.

\subsection{Softwares used}

BLUE KENUE: BLUE KENUE is open source software which is used to generate grids and triangular mesh. In will take the input data in the form arc view file type like points, lines and polygons.

SMS: SMS (EMRL 2006) is a pre and post-processor for surface water modelling developed by the Environmental Modelling Research Laboratory (EMRL). It is commercial software where a user can generate mesh by assigning boundary conditions and model parameters.

ArcGIS: ArcGIS is a geographic data framework (GIS) for working with maps and geographic data. It is utilized for making and utilizing maps, ordering geographic information, breaking down mapped data, sharing and finding geographic data, utilizing maps and geographic data in a scope of uses, and overseeing geographic data in a database.

\section{METHODOLOGY}

Firstly Bathymetry Data is collected from GEBCO and extracting bathymetry using arc map and zero contour line (coastline) is also extracted from arc map. The next step is to generate the mesh for the domain region.

For the generation of mesh in blue Kenue (open source), boundaries are created for both land and ocean. The created layers are assigned with the reference coordinate system. The Boundary is refined for accuracy purpose.

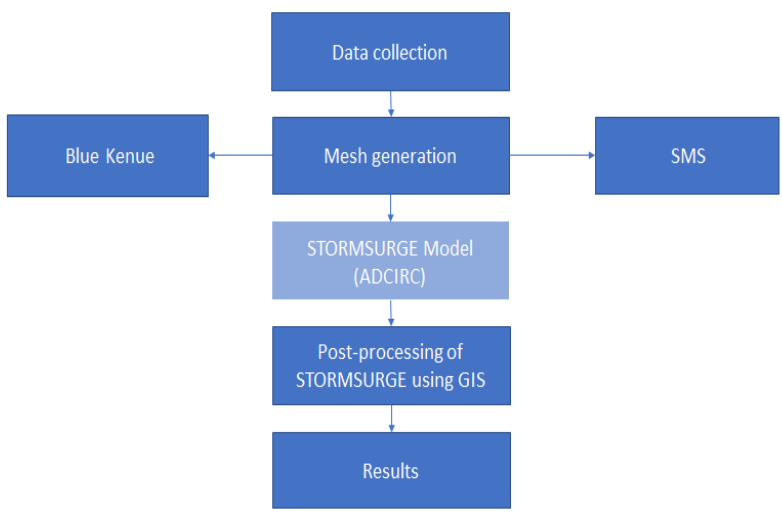

Figure2. Flowchart of methodology

Fine refinement is given near coastline as information near the coastline is important. From coast to boundary, refinement is increased from fine to coarse. A model domain for the whole boundary (including land and ocean) is created and bathymetry points are extracted within the domain. A new T3Mesh is generated for both land and ocean. Meshes of both land and ocean are merged and bathymetry points are interpolated.

For the generation of mesh in SMS (commercial), a coastline file is read to define the domain and assigning the boundary type. Then the coastline file is edited with reference co3ordinate system. Reading in the bathymetry file and defining shallow wavelength functions. Creating the size function and generating mesh for the defined polygon.

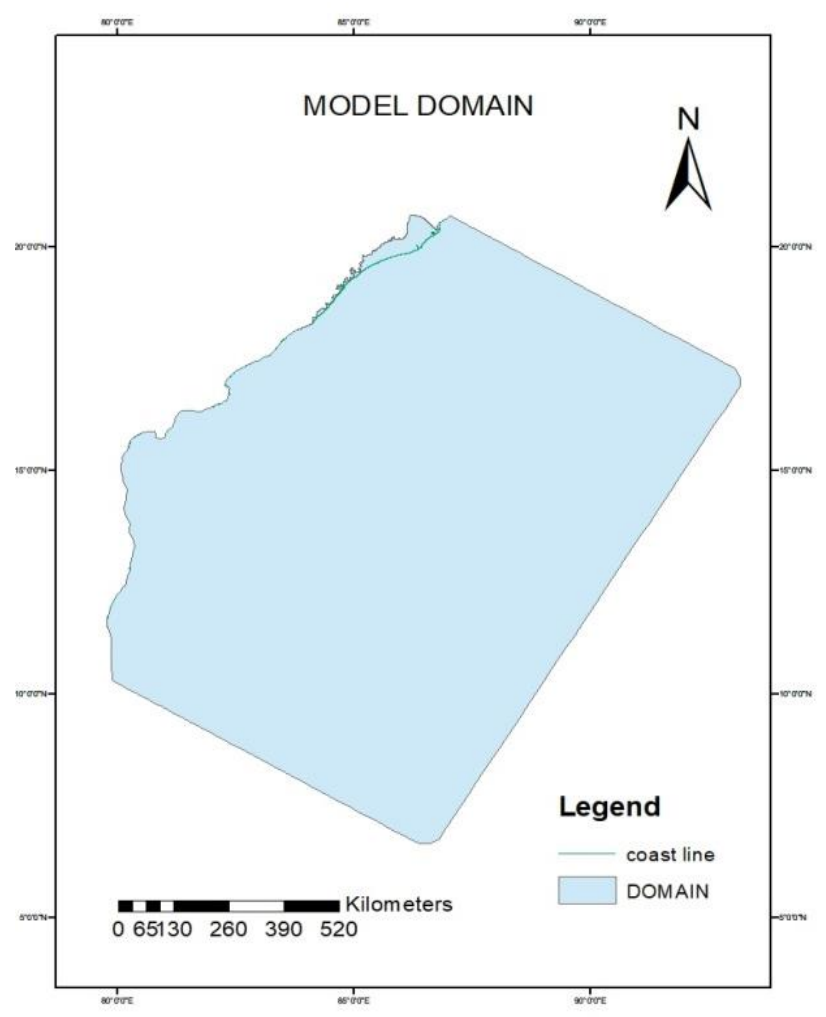

Figure3. Model domain 


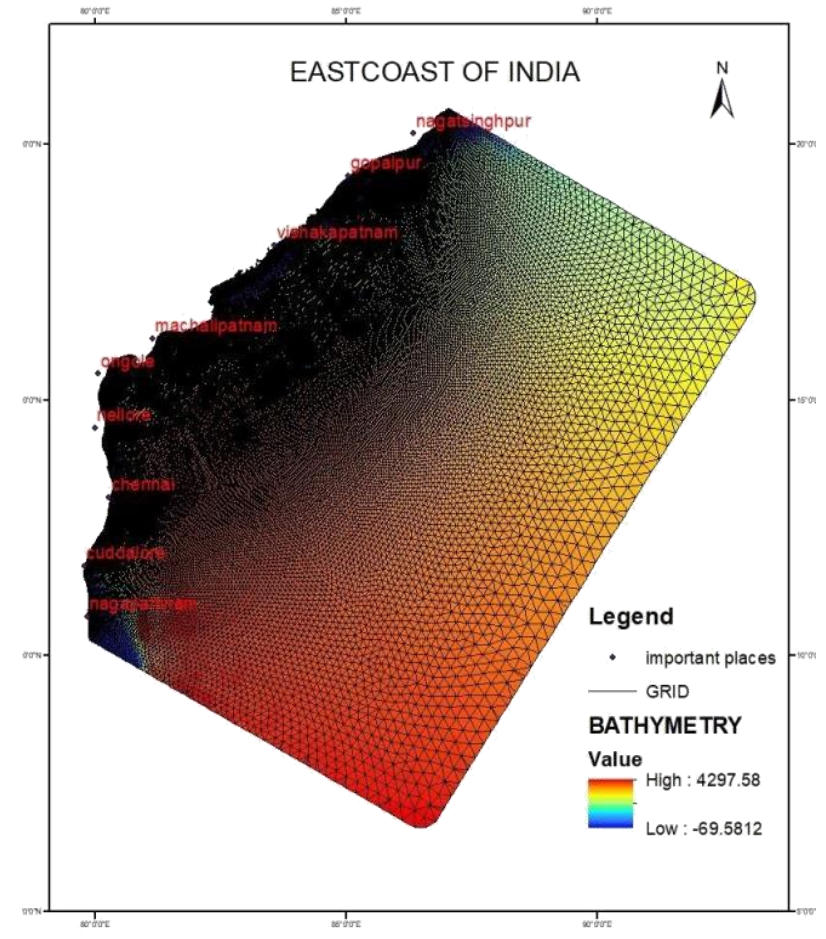

Figure4. Mesh generated for the east coast of India

The generated mesh is used as the base layer for storm surge modelling. In the present study, the outputs from storm surge model (ADCIRC) are fort.14 and maxele.63 which do not support the ARCGIS format hence conversion of this fort.14 and maxele.63 into arc shapefiles is done. Then a new TIN (Triangulated Irregular Network) is created using CREATE TIN $3 \mathrm{D}$ analyst tool giving point shapefiles as input and specifying output file. The created tin is edited with the boundary shapefile to remove unwanted elements using EDIT TIN 3D analyst tool. This TIN's are converted into raster by using TIN to RASTER conversion tool using linear interpolation. From the raster by performing raster calculation, values greater than zero are made zero and by summing up with run-up we get pre-inundation values. Set null is performed for pre-inundation values which are less than zero to obtain inundation. To obtain inundation outline we use RASTER DOMAIN 3D analyst tool.

Storm surge and inundation extent have been computed for Hudhud and Phailin cyclones as the Coastal states along the east coast of India are frequently threatened by storm surge associated with land-falling tropical cyclones (Mohanty, 2016.). The loss of life and property gets multiplied by the sea water inundates coastal areas and these problems can be defended by taking preventive measures (Murty et al.).

\section{RESULTS}

Post processing of storm surge during Phailin and Hudhud cyclones is done using ARCMAP (as shown in Figure5. \& Figure6.)

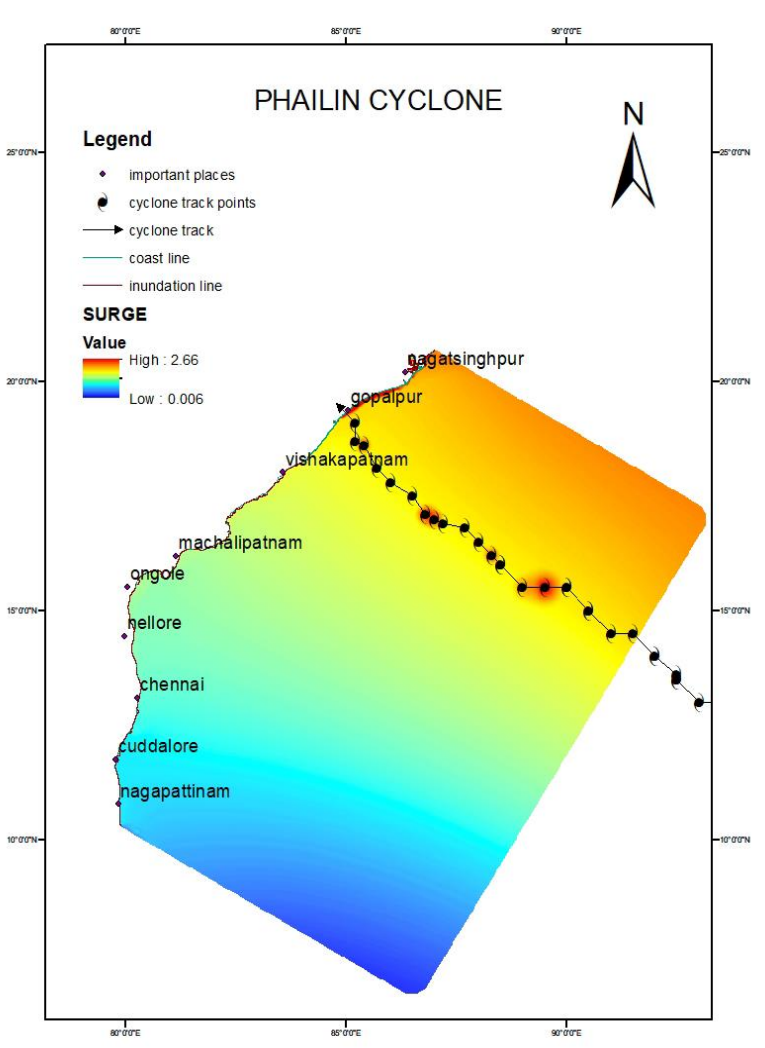

Figure5. Phailin cyclone

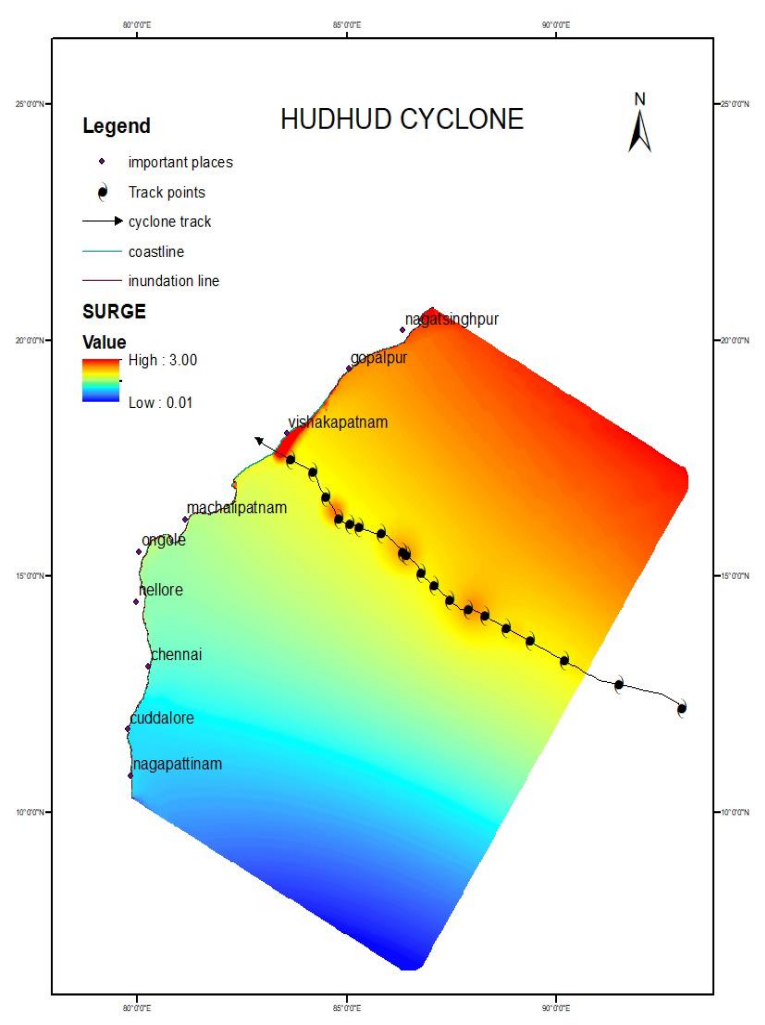

Figure6. Hudhud cyclone 


\subsection{Peak Surge}

Peak surge during Phailin cyclone occurred in the region Gopalpur which is located at $85.044^{\circ}$ E longitude, $19.377^{\circ} \mathrm{N}$ latitude as shown in Figure7.

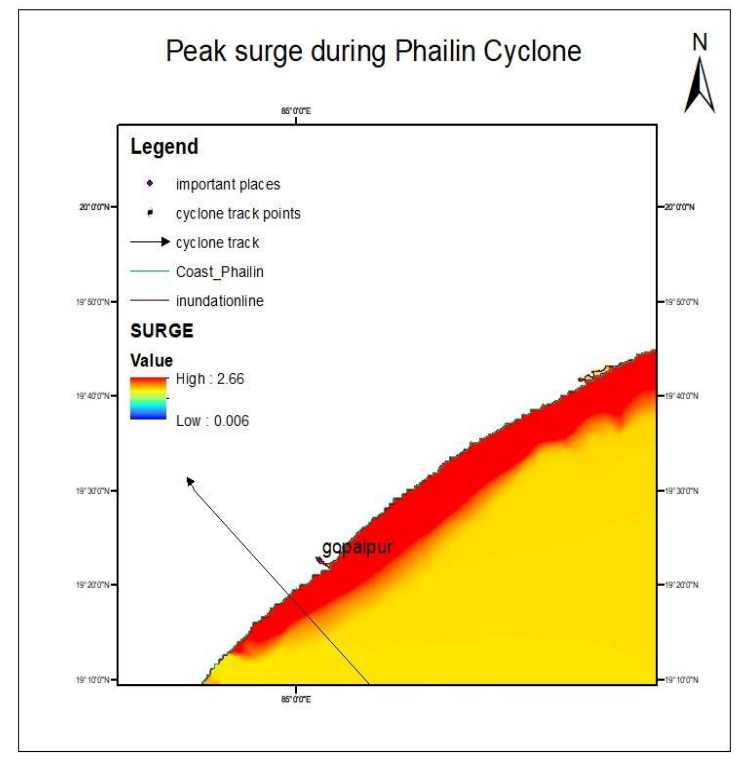

Figure7. Peaksurge during Phailin cyclone

Peak surge during Hudhud cyclone occurred in the region Vishakhapatnam which is located at $83.569^{\circ} \mathrm{E}$ longitude, $18.013^{\circ} \mathrm{N}$ latitude as shown in Figure8.

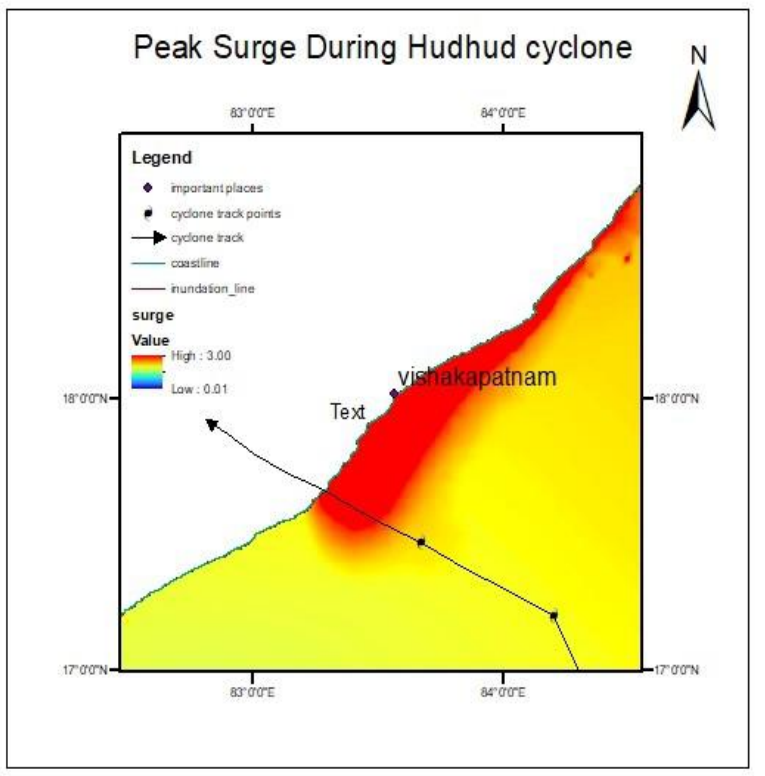

Figure8. Peaksurge during Hudhud cyclone

\subsubsection{Run-up Height}

Run-up height for Phailin cyclone is $6.559 \mathrm{~m}$ as shown in Figure9.

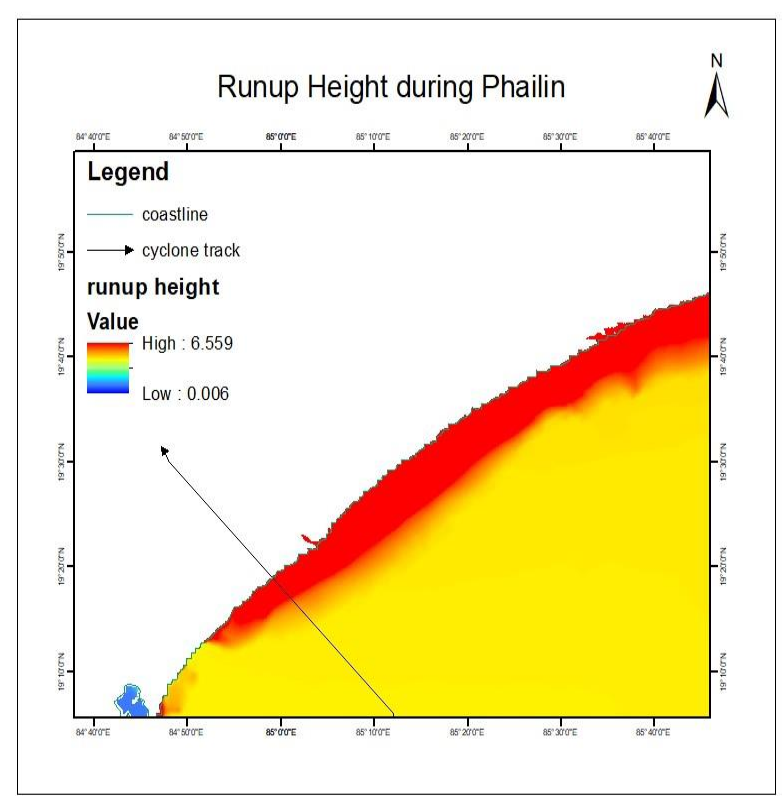

Figure9. Run-up height during Phailin cyclone

Run up height for Hudhud cyclone is $3.644 \mathrm{~m}$ as shown in Figure10.

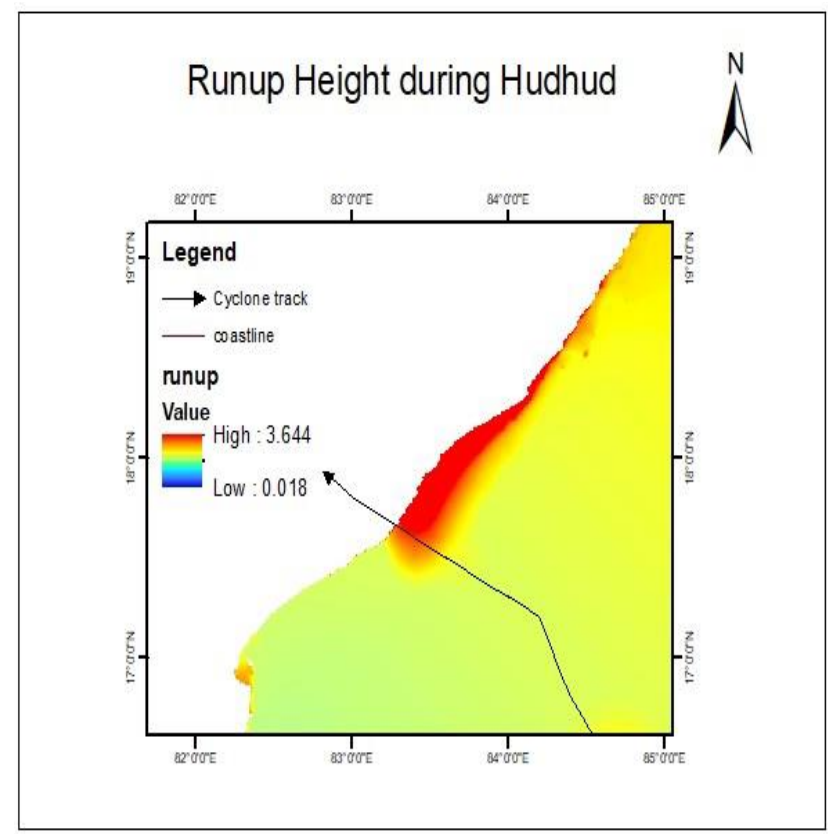

Figure10. Run-up height during Hudhud cyclone

\subsubsection{Surge Height}

The maximum surge height during Phailin cyclone is $2.66 \mathrm{~m}$ as shown in Figure11. 


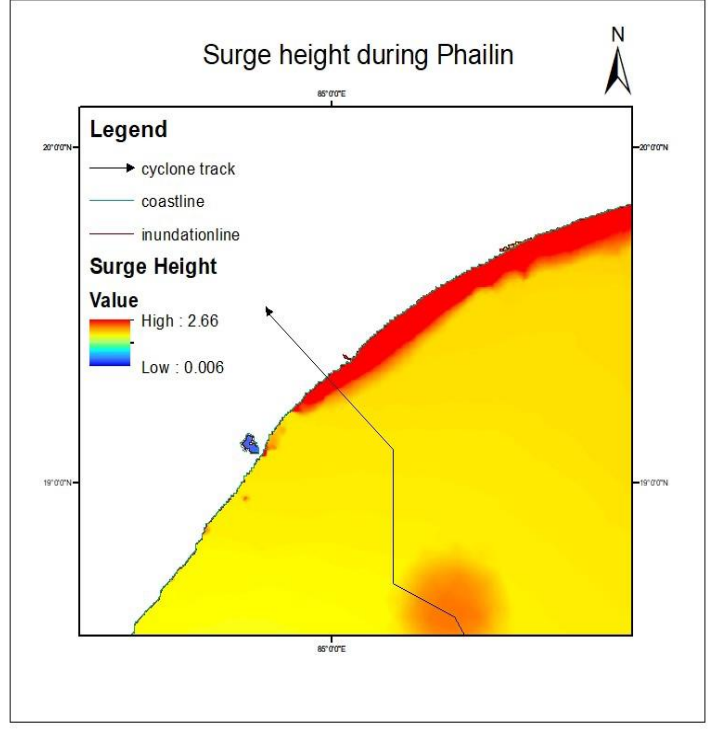

Figure11. Surge height during Phailin cyclone

The maximum surge height during Hudhud cyclone is $3 \mathrm{~m}$ as shown in Figure12.

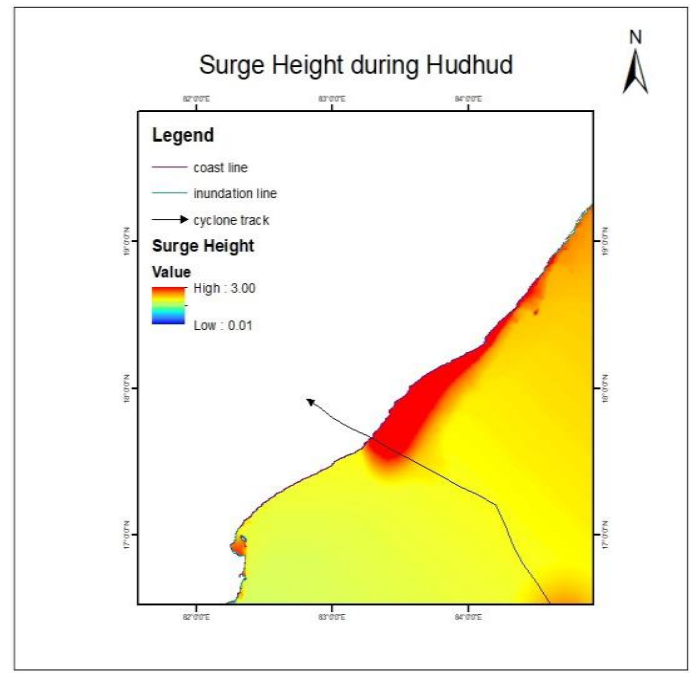

Figure12. Surge height during Hudhud cyclone

\subsection{Inundation Extent}

Maximum Inundation extent for Phailin cyclone is $3969.22 \mathrm{~m}$ in the region of Gopalpur $\left(85.044^{\circ} \mathrm{E}\right.$ longitude, $19.377^{\circ} \mathrm{N}$ latitude) as shown in Figure13.

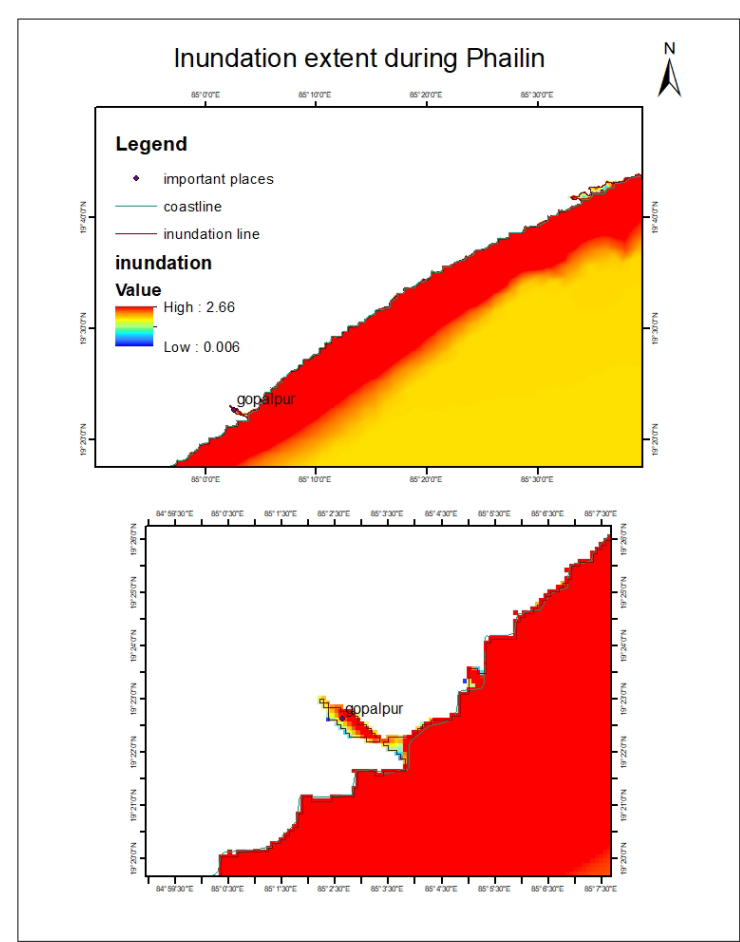

Figure13. Inundation extent during Phailin cyclone

Maximum Inundation extent for Hudhud cyclone is 822 meters near the region of Vishakhapatnam $\left(83.569^{\circ} \mathrm{E}\right.$ longitude, $18.013^{\circ} \mathrm{N}$ latitude) shown in Figure14.

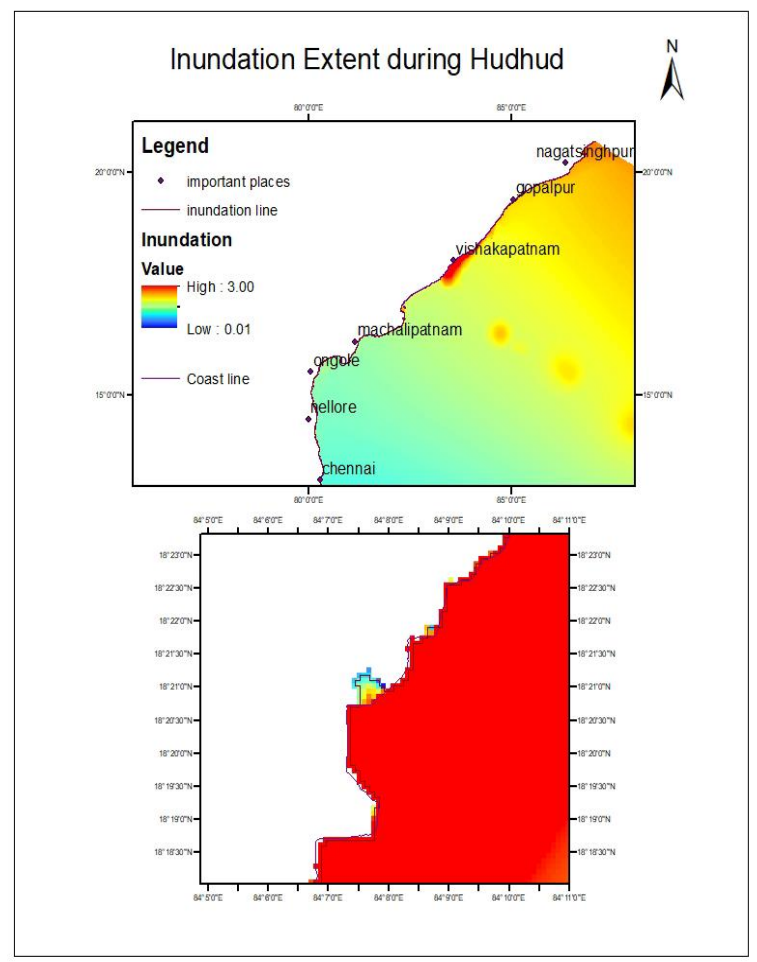

Figure14. Inundation extent during Hudhud cyclone 


\subsection{Inundation Area}

Inundation area is around $35.8 \mathrm{~km}^{2}$ for Phailin cyclone. The area inundated during Phailin cyclone is as shown in Figure15.

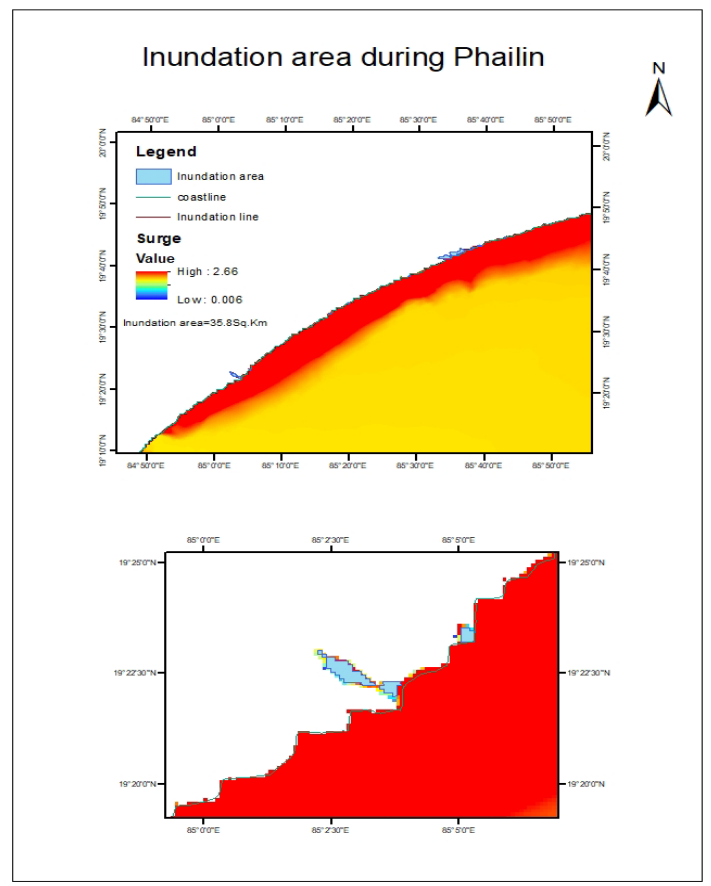

Figure15. Inundation area during Phailin cyclone

Inundation area is around $7.29 \mathrm{~km}^{2}$ for Hudhud cyclone. The area inundated during Hudhud cyclone is as shown in Figure16

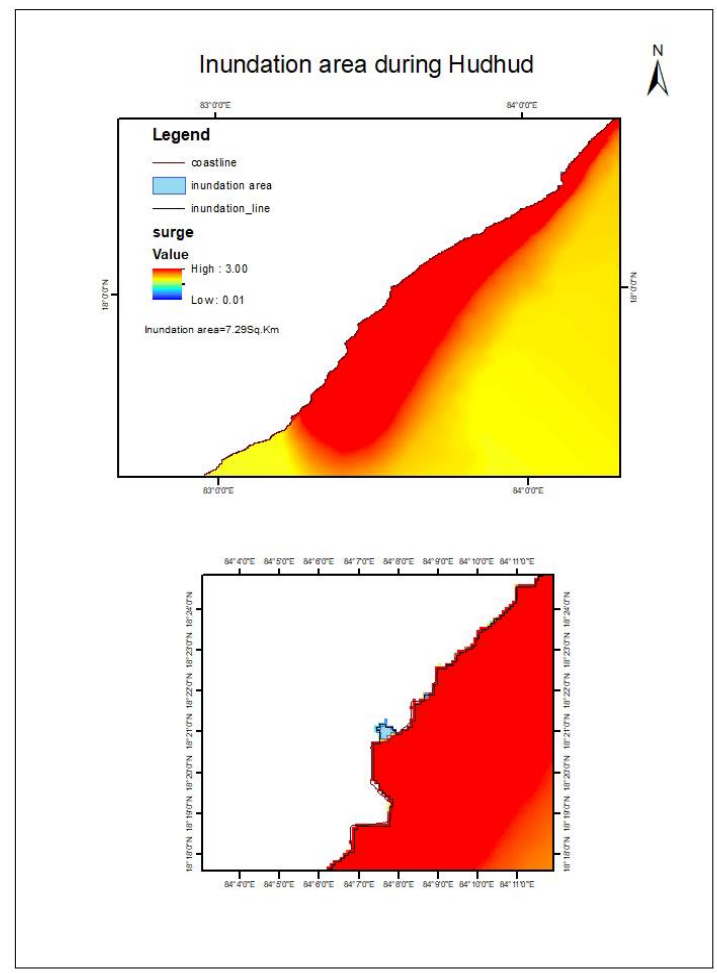

Figure16. Inundation area during Hudhud cyclone

\section{CONCLUSION}

Post processing of Storm Surge using GIS is done after the simulations of storm surges and associated inundation during very severe cyclone storms Hudhud and Phailin along the east coast of India. In both Hudhud and Phailin cases, computed Peak surges are almost same however the Inundation extent is different. This could be due to the different nature of nearshore bathymetry and onshore topography around Vishakhapatnam and Gopalpur regions where Hudhud and Phailin made their landfall respectively. Hence for the realistic computations of surge heights as well as inundation extents, accurate nearshore bathymetry and on shore topography have to be provided to the model.

\section{REFERENCES}

Das, P. K., 1972."Prediction model for storm surges in the Bay of Bengal.” Nature,239(5369), 211.

Dube, S. K., Murty, T. S., Feyen, J. C., Cabrera, R., Harper, B. A., Bales, J. D., \&Amer, S., 2010.“Storm surge modeling and applications in coastal areas."Global Perspectives on Tropical Cyclones: From Science to Mitigation pp. 363-406.

Ferreira, Celso M., Francisco Olivera, and Jennifer L. Irish., 2014."Arc Storm Surge: Integrating hurricane storm surge modelling and GIS." JAWRA Journal of the American Water Resources Association 50.1: 219-233.

Lakshmi, D. D., Murty, P. L. N., Bhaskaran, P. K., Sahoo, B., Kumar, T. S., Shenoi, S. S. C., \& Srikanth, A. S. (2017). "Performance of WRF-ARW winds on computed storm surge using hydodynamic model for Phailin and Hudhud cyclones."Ocean Engineering, 131, 135-148.

Mohanty, Uma Charan, and Sundararaman G. Gopalakrishnan, eds(2016). "Advanced Numerical Modeling and Data Assimilation Techniques for Tropical Cyclone Predictions". Springer.

Murty .P.L.N., Sandhya K.G., Prasad K. Bhaskaran, Felix Jose , R. Gayathri , T.M. Balakrishnan Nair ,T. Srinivasa Kumar, S.S.C. Shenoi., 2014. "A coupled hydrodynamic modeling system for PHAILIN cyclone in the Bay of Bengal" Coastal Engineering 93:71-81

Murty.P.L.N., Prasad K., Bhaskaran, R. Gayathri, BishnupriyaSahoo,T. Srinivasa Kumar, B. SubbaReddy., 2016. "Numerical study of coastal hydrodynamics using a coupled model for Hudhud cyclone in the Bay of Bengal" Estuarine, Coastal and Shelf Science 183:13-27.

Murty. P. L. N., J. Padmanabham, T. Srinivasa Kumar, N. Kiran Kumar, V. Ravi Chandra, S. S. C. Shenoi, and M. Mohapatra.(2017) "Real-time storm surge and inundation forecast for very severe cyclonic storm 'Hudhud'." Ocean Engineering 131: 25-35. 